\title{
INFORMATION SYSTEMS: PERFORMING APPLICATION-SPECIFIC ASSESSMENT OF STUDENT PERFORMANCE
}

\author{
Sharon Paranto, Northern State University, parantos@northern.edu \\ Hillar Neumann, Northern State University, hnj@northern.edu \\ Lu Zhang, Northern State University, luz@northern.edu
}

\begin{abstract}
This paper is an expansion of a previous study in which the authors described the results of using a simulated testing package to assess student performance in an advanced computer applications course. In the original study, a pre-test/post-test format was utilized in assessing whether the level of knowledge and skills possessed by students who completed the advanced course increased significantly when compared to the knowledge and skills the students possessed when entering the course. A student assessment tool that uses a simulated environment for testing was used to measure each student's level of knowledge and expertise both at the beginning of the course and at the conclusion of the course. The pre-/post-test process was not only useful in providing a measure of the learning that took place, but also in providing evidence that the intended outcomes of the technology component of the business core were achieved. However, faculty felt that it was important to expand the study by breaking the pre-/post-test scores down by software application (i.e. word processing, database applications, presentation software, spreadsheets, and Internet use/website development). This paper includes the breakdown of scores, and the corresponding statistical analyses, by topic area.
\end{abstract}

Keywords: Assessment, Pre/Post-testing, Accreditation, Information Systems Accreditation, Information Systems Assessment

\section{INTRODUCTION}

According to the Association to Advance Collegiate Schools of Business, AACSB International, "measures of learning can assure external constituents such as potential students, trustees, public officials, supporters, and accreditors, that the organization meets its goals” [4, pg. 60]. In recent years, there has been a strong emphasis at the university involved in this study on providing course level assessments for accreditation purposes. Although the AACSB standards focus on program level assessment [1], the AACSB organization recognizes the need for course-level assessments. According to an interpretation of the AACSB standards, "course-level assessments are each faculty member's responsibility” [2, pg. 4]. Similarly, a central theme in Higher Learning Commission (HLC) accreditation is the focus on commitment to student learning and the meaningful use of assessment to confirm and improve student learning [7].

Prior to the Spring 2007 semester, a general content multiple choice exam had been used to assess whether learning did in fact take place in the advanced applications course. The post-test scores were useful in providing a measure of the level of learning that took place and evidence that the intended outcomes of the technology component of the business core were achieved [10, 11]. However, the exam included general computer knowledge that all college graduates should possess rather than content that was specific to this particular class. The multiple choice exam provided statistical data to indicate that students scored significantly higher at the conclusion of the class than they did at the beginning of the course, but the faculty felt it would be advantageous to have an exam that covered the specific topic areas and skills taught in the advanced applications course.

Schuh noted that the emphasis on technology in schools in recent years has changed from providing students with "access to technology to giving them the skills they need to live, work, and learn in an increasingly digital world" [12, pg. 1]. Advanced Computer Applications is a core course required of all business majors at the university described in this study. The course is designed to provide business students with some of the skills needed to survive in this increasingly digital world. This paper describes the pre-test/post-test format was utilized in assessing whether the level of knowledge and skills possessed by students who completed the advanced course increased significantly when compared to the knowledge and skills the students possessed when entering the course. The paper also provides statistical analyses, by topic area, which were used to 
assess whether the level of knowledge and skills, by topic area, possessed by students who completed the advanced course increased significantly when compared to the knowledge and skills, by topic area, the students possessed when entering the course.

\section{LITERATURE REVIEW}

Although an abundance of information is available related to assessment, little information is available providing statistical comparisons of assessment data in the form of pre-/post-testing of skills related to software applications in the information systems field. It is common knowledge that students enter colleges and universities with a wide range of computer knowledge and skills. Before students can develop a high degree of computer skills proficiency, they need to have a certain level of computer literacy. Merritt, Smith, and Di Renzo [8] examined the question of whether self-reported computer literacy can be a reliable indication of actual computer literacy. They asked participants to self-report their level of computer literacy and then tested the subjects to determine an objective measure of computer literacy. The results indicated that self-reported computer literacy is not a reliable method to use for placement of students into the appropriate level of computer course (e.g. introduction to computers versus advanced computer applications).

Fleck, McQueen, and Whitehead [5] evaluated skill assessment products offered by several vendors. They noted that two separate issues, 1) finding a method for pre-evaluations and placement and 2) testing during the course, may have common solutions if the testing reflects acceptable outcome measures. They also emphasized that in order to develop appropriate outcome measures, it is necessary to have a clear understanding of curriculum and employment objectives. The outcome measures, combined with available resources, should drive the process in terms of selecting an appropriate assessment product versus developing an in-house examination. Similarly, Gratch-Lindauer [6, pg. 36] noted that the specific learning outcomes to be assessed usually determine the instrument and method that is used for assessment.

Valenti, Cucchiarelli, and Panti [15] found that interest in developing computer-based assessment systems has increased in recent years, which can be useful to educators when selecting the most appropriate tool for their assessment needs. They pointed out that little scientific literature is available related to computer-based assessment systems, but they also provided a series of factors that should be considered by educators when evaluating computerbased assessment systems, using the ISO 9126 standard for evaluation of software quality characteristics.

When developing an assessment plan, Sonntag and Meulemans [14] indicate that we must decide what we will be assessing and how it will be assessed. They stress the importance of focusing on learning outcomes. They also point out that assessing student knowledge (what the student knows) is not necessarily the same as assessing student skills (what the student can do). Thus, it becomes important to find ways to assess not only what a student knows (knowledge) but also what a student can do (skills).

Moskal [9], in her recommendations for developing performance assessments, recognized that performance assessments can take on many forms, including activities that can be completed. She noted that through observation or analysis of a student's response, an instructor can determine what the student knows and does not know. She also emphasized the importance of using performance assessment results to improve future classroom instruction, as well as the assessment process.

\section{PURPOSE/BACKGROUND}

The purpose of this study was to assess whether the level of knowledge and skills possessed by students who completed an advanced computer applications course increased significantly when compared to the knowledge and skills the students possessed when entering the course. The faculty started the process by meeting to discuss which skills were of utmost importance for business students, in order to determine the desired outcomes. Many of the learning objectives in the advanced applications course focus on the skills needed to become proficient in common business application packages, such as word processing, spreadsheets, database management, presentation software, and effective use of the Internet and website development tools. The textbook that was selected for the course included objectives for each topic area (skill set) that matched the desired outcomes established by the faculty.

The outcomes that were established were also used to determine the key concepts and skills that were to be included in the comprehensive final. Once this determination was made, a student assessment tool that uses a simulated environment for testing was used to develop the exam. SAM (Skills Assessment Manager), a Web-based software application that measures users' proficiency in the Microsoft Office applications suite (Access, Excel, PowerPoint and 
Word), the Windows operating system, and general Internet skills [13], was selected. There are other assessment tools available, such as the McGraw-Hill SimNet package. For this study, the SAM tool was selected simply because it meshed well with the textbook that was selected for the course.

All faculty had an opportunity to recommend changes to the draft exam that was developed. At the beginning of the Spring 2007 semester, when the final version of the exam was ready to go, the pre-/post-test process that utilized the simulation testing package was implemented. The specific task instructions utilized in the testing are included in Appendix A. Keep in mind that the simulated testing package opens the applicable software application; displays a document, such as a spreadsheet or a word processing document; and tracks the keystrokes and options selected by students as they complete each task specified in the instructions.

\section{METHODOLOGY}

The pool of students used to assess learning in the advanced computer applications course was taken from the Spring and Fall 2007 and the Spring 2008 semesters. There were three sections of seventy (70) students who completed the course in the Spring 2007 semester, all taught by the same instructor. In Fall 2007, there were three sections of sixty two (62) students taught by two instructors and in the Spring 2008 semester, there were four sections of sixty seven (67) students taught by two instructors. Thus, a total of 199 students participated in this study.

At the beginning of the semester each student took an in-class pre-test over the specific material to be covered in each topic area of the course. Subsequently, at the end of the semester each student took a post-test over the same material. This posttest was the comprehensive final used in the advanced applications course. The pre- and post-tests were identical. Statistical analyses were conducted on the results. Faculty members were especially interested in comparing the statistical difference in the pre- and post-test results by topic area.

\section{STATISTICAL RESULTS}

Table 1 provides the descriptive statistics for the sample of 199 students, which covers three semesters from spring, 2007 through spring, 2008. This table reports the pre and post mean, median, standard deviation, and minimum/maximum individual scores for each category of skills and the total exam score. The post mean and median scores in the exam total and the individual skill categories all exceed that of their pre-test score. In all but one case (Presentation Software) the standard deviations of the post-test score exceed that of the pre-test score. Variation in the post-test score typically exceeds that of the pretest score.

Included in Table 1 are the minimum and maximum individual scores for the total score and each subcategory. The reader may find it constructive to compare Table 1 with the box plots presented in Figures 1 through 6 . The individual exam total pretest score ranged from a minimum of $5.0 \%$ to maximum of $72.50 \%$, whereas the individual posttest scores ranged from a minimum of $32.50 \%$ to a maximum of $100 \%$. Comparing the box plots between pre- and post-test scores clearly demonstrate the post-test score results exceed the pre-test score. The reader is asked to compare the pre/post minimum and maximum test scores for the sub-category technical skills scores.

Table 1. Sample Descriptive Statistics

\begin{tabular}{lrrrrrr}
\hline & Total & $\begin{array}{c}\text { Word } \\
\text { Processing }\end{array}$ & Spreadsheets & $\begin{array}{c}\text { Database } \\
\text { Applications }\end{array}$ & $\begin{array}{c}\text { Presentation } \\
\text { Software }\end{array}$ & $\begin{array}{c}\text { Internet/ } \\
\text { Website Dev. }\end{array}$ \\
\hline Mean - Pre & $31.19 \%$ & $28.92 \%$ & $13.85 \%$ & $24.69 \%$ & $38.91 \%$ & $52.20 \%$ \\
Mean - Post & $70.23 \%$ & $59.91 \%$ & $47.12 \%$ & $77.60 \%$ & $89.23 \%$ & $84.74 \%$ \\
Median - Pre & $30.00 \%$ & $22.22 \%$ & $11.11 \%$ & $14.29 \%$ & $42.86 \%$ & $50.00 \%$ \\
Median - Post & $70.00 \%$ & $55.56 \%$ & $44.44 \%$ & $85.71 \%$ & $100.00 \%$ & $87.50 \%$ \\
St.Dev. - Pre & $11.34 \%$ & $15.39 \%$ & $12.76 \%$ & $19.35 \%$ & $24.53 \%$ & $17.06 \%$ \\
St.Dev. - Post & $14.63 \%$ & $17.14 \%$ & $27.29 \%$ & $21.27 \%$ & $14.95 \%$ & $18.25 \%$ \\
Min - Pre & $5.00 \%$ & $0.00 \%$ & $0.00 \%$ & $0.00 \%$ & $0.00 \%$ & $0.00 \%$ \\
Min - Post & $32.50 \%$ & $11.11 \%$ & $0.00 \%$ & $14.29 \%$ & $0.00 \%$ & $25.00 \%$ \\
Max - Pre & $72.50 \%$ & $77.78 \%$ & $55.56 \%$ & $85.71 \%$ & $100.00 \%$ & $100.00 \%$ \\
Max - Post & $100.00 \%$ & $100.00 \%$ & $100.00 \%$ & $100.00 \%$ & $100.00 \%$ & $100.00 \%$ \\
\hline
\end{tabular}




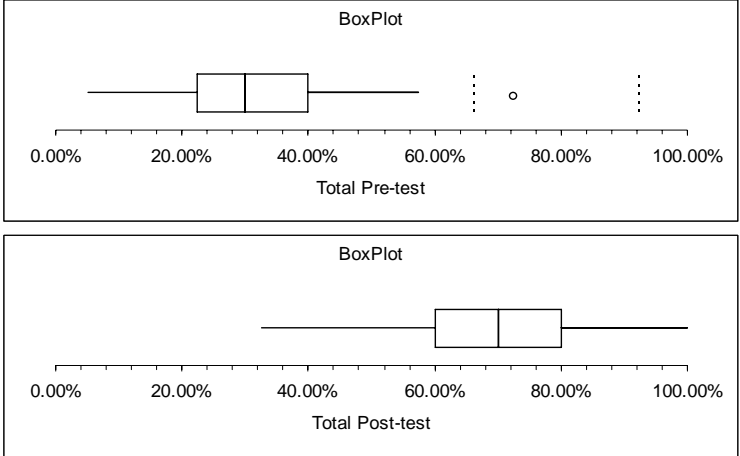

Figure 1. Exam Total Pre-/Post-Test Box Plots

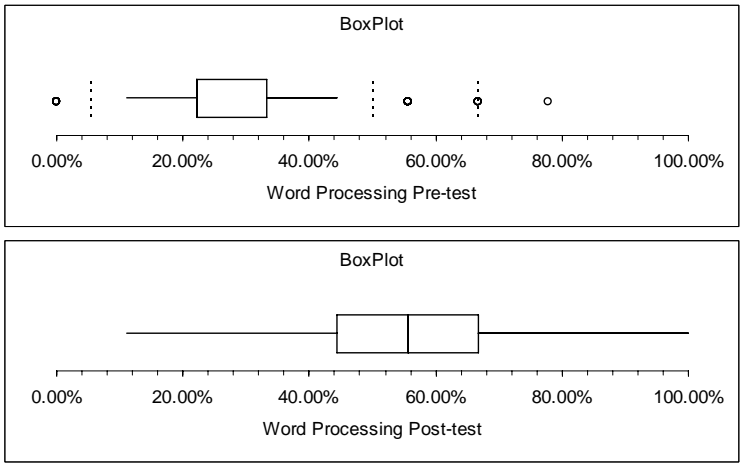

Figure 2. Word Processing Pre-/Post-Test Box Plots

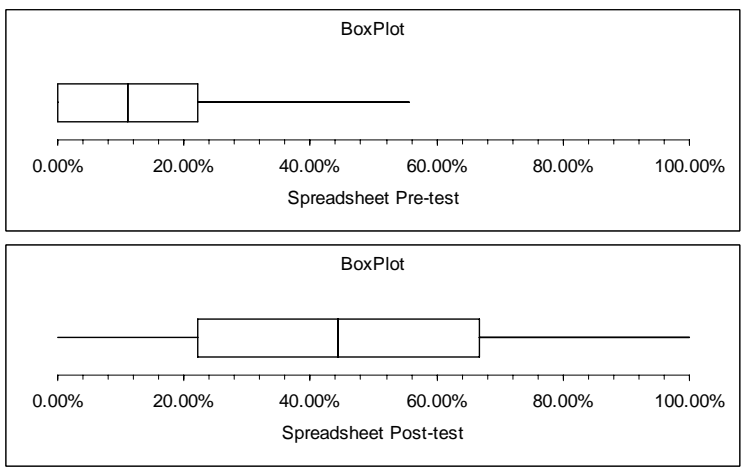

Figure 3. Spreadsheets Pre-/Post-Test Box Plots

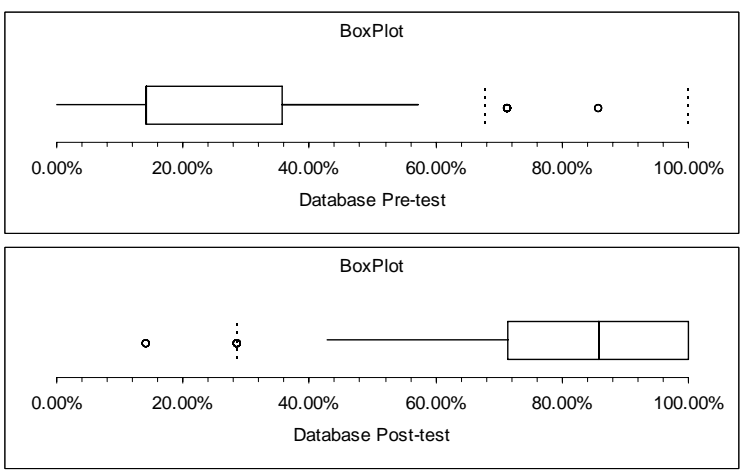

Figure 4. Database Pre-/Post-Test Box Plots

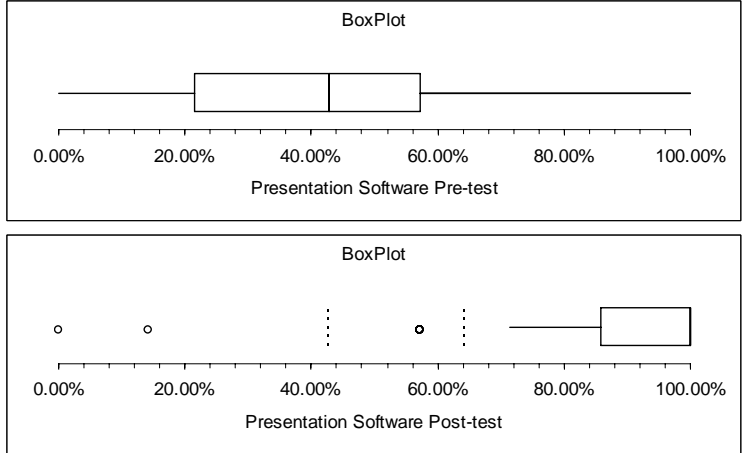

Figure 5. Presentation SW Pre-/Post-Test Box Plots

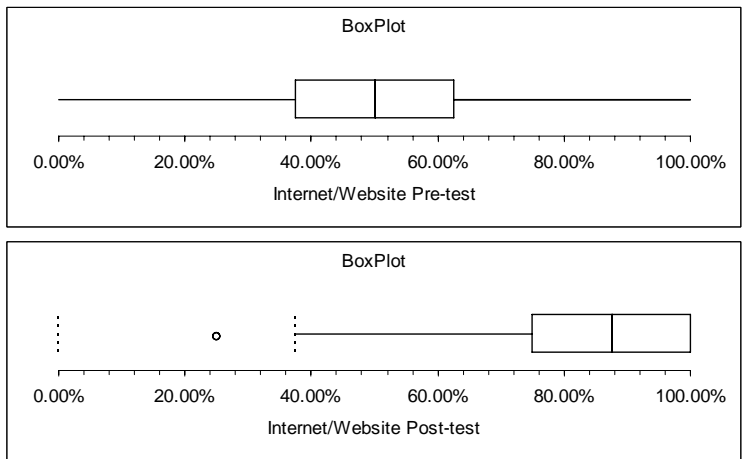

Figure 6. Internet/Website Pre-/Post-Test Box Plots

\section{Statistical Tests of Differences in Means:}

Our research centered upon the following research question: For each topic area, was there a significant increase in the mean score of the post-test when compared to the mean score of the pre-test?

The null hypothesis $\left(\mathrm{H}_{0}\right)$ is "the difference between the mean score for the post-test and the pre-test is zero" versus the alternative hypothesis $\left(\mathrm{H}_{1}\right)$ that "the difference between the mean score of the post-test and the mean score of the pre-test exceeds zero.” The null and alternative hypotheses for each category are as follows:

$\mathrm{H}_{0}$ : The Post-Test Mean Score Equals the Pre-Test Mean Score

$\mathrm{H}_{1}$ : The Post-Test Mean Score Exceeds the Pre-Test Mean Score

Table 2 presents the statistical results for the tests of differences in means. This table provides the t-statistics for the difference in means for the pre- and post-test score and the probability value. We arbitrarily set the level of significance at $1.0 \%(.01)$ with 197 degrees of freedom. The critical $t$ is +2.3454 . 
Table 2. t-Test for Differences in Means

(Critical t at a level of significance of $1 \%$ is 2.3454 )

\begin{tabular}{|c|c|c|c|c|c|c|}
\hline & Total & $\begin{array}{c}\text { Word } \\
\text { Processing }\end{array}$ & Spreadsheets & $\begin{array}{c}\text { Database } \\
\text { Applications }\end{array}$ & $\begin{array}{c}\text { Presentation } \\
\text { Software }\end{array}$ & $\begin{array}{c}\text { Internet/ } \\
\text { Website Dev. }\end{array}$ \\
\hline t-statistic & 35.17 & 21.18 & 17.55 & 30.07 & 25.89 & 19.62 \\
\hline Prob-Value & 2.17 E-87 & $4.42 \mathrm{E}-53$ & $1.61 \mathrm{E}-42$ & 4.67 E-67 & 9.11 E-66 & 1.31 E-48 \\
\hline
\end{tabular}

As reported in Table 2, in each case the null hypothesis that the pre- and post-test means are equal must not be accepted (i.e. is rejected). An alternative probability value approach clearly supports the rejection of the null hypothesis. The probability values in each case are extremely small, further supporting the conclusion that the post-test mean score exceeds the pre-test mean score. The statistical results support the hypotheses that the level of knowledge and skills possessed by students at the end of the course, both overall and by topic area, were significantly higher than the knowledge and skills possessed by students at the beginning of the course.

\section{OUTCOMES}

According to an Interpretation of AACSB Assurance of Learning Standards, "Regardless of the assessment tool that is selected for each learning goal, an acceptable, internal performance benchmark should be established to determine if student performance is acceptable or not. Such a benchmark could be based on the judgment of faculty or a pre-determined standard could be established" [3, pg. 11]. Due to the difficulty of the exam and the standard of using $60 \%$ as a passing score for the class, the following benchmark was established by the department: at least $75 \%$ of the students completing the advanced applications course will score at or above $60 \%$ on the Information Systems technology-related post-test.

Table 3. Outcomes Assessment

\begin{tabular}{lccc}
\hline Score & \# Students & Percentage & Cumulative $^{\mathbf{1}}$ \\
\hline $90-100 \%$ & 28 & $14.1 \%$ & $14.1 \%$ \\
$80-<90 \%$ & 25 & $12.6 \%$ & $26.7 \%$ \\
$70-<80 \%$ & 52 & $26.1 \%$ & $52.8 \%$ \\
$60-<70 \%$ & 49 & $24.6 \%$ & $77.4 \%$ \\
$<60 \%$ & 45 & $22.6 \%$ & $100.0 \%$ \\
\hline Totals & 199 & $100.0 \%$ & \\
\hline
\end{tabular}

${ }^{1}$ The Cumulative column indicates the percentage of students with scores greater than or equal to the Score range indicated.

Table 3 provides a breakdown of the post-test percentage scores for the advanced computer applications course. As the data indicate, $77.4 \%$ of the students who completed the post-test scored at or above $60 \%$ on the exam, which satisfies the criteria established by the department. However, when the scores were broken down by topic area, we found that the mean student score on the spreadsheet component of the post-test was $47.12 \%$. This is an area of concern. The course content, the corresponding pedagogy, and the test itself will have to be reevaluated to determine what course of action should be taken to identify and fix the problem area. Data will continue to be collected and evaluated from semester to semester, to determine whether student scores continue to meet the established outcomes. Also, due to the ever-changing nature of technology, the exam will need to be evaluated and revised on an annual basis, as the content of the course continues to evolve to keep pace with technology and the everchanging needs of the business environment.

\section{SUMMARY}

The statistical analyses on the pre- and post-tests for the three semesters support the hypothesis that there was a significant improvement when comparing the mean of the post-test with the mean of the pre-test. Overall, the summary statistics support the contention that students in the advanced computer applications course did learn a significant portion of the material. Similarly, analyses of the breakdown of scores by topic area support the contention that students learned a significant portion of the skill sets covered in each topic area. An added benefit of the process is that the results provide assessment agencies with evidence of student learning.

As noted above, students scored much higher in some topic areas than in others. This will have to be studied and changes will be made in an effort to increase student scores in the specific topic area of concern. Future assessment analyses will be necessary to continue to test learning and to identify weaknesses in student performance. Clearly, faculty can acquire vital information from the assessment data which they can in turn use to strengthen their course. The pre-/post-test process will continue to be used to evaluate the information systems component of the business core curriculum. Correspondingly, the results will continue to be incorporated into the annual assessment report and will continue to be utilized in modifying the course content and/or the corresponding pedagogy and/or the test itself, as deemed necessary. 


\section{REFERENCES}

1. AACSB. (2008). AACSB Accreditation Standards. [online] Available: www.aacsb.edu/ resource_centers/assessment/standards.asp

2. AACSB. (2007). AACSB Assurance of Learning Standards: An Interpretation. Nov. 20, 2007, p. 4. [online] Available: www.aacsb.edu/ accreditation/papers/aolpaper-final-11-20-07.pdf

3. ibid, p. 11.

4. AACSB. (2007). Eligibility Procedures and Accreditation Standards for Business Accreditation. Tampa, Fla. AACSB International, p. 60.

5. Fleck, R., McQueen, T., and Whitehead, C. (2002). An Evaluation of Office XP Skill Assessment Tools. Rock Eagle 2002 University System Annual Computing Conference Proceedings. Published by the University System of Georgia.

6. Gratch-Lindauer, B. (2003). Selecting and Developing Assessment Tools. In E. Fuseler Avery (Ed.), Assessing Student Learning Outcomes for Information Literacy Instruction in Academic Institutions (pp. 22-39). Association of College and Research Libraries, a Division of the American Library Association, Chicago.

7. HLC. (2007). Assessment Student Learning March 07: Student Learning, Assessment, and Accreditation, March 2007. [online] Available: www.ncahlc.org/index.php?option=com_docma n\&task $=$ cat_view\&Itemid=229\&gid=79

8. Merritt, K., Smith, K.D., and Di Renzo, J. (2005). An Investigation of Self-reported computer literacy: Is it Reliable? Issues in Information Systems, VI(1), 2005. Published by the International Association for Computer Information Systems.

9. Moskal, B. (2003). Recommendations for Developing Classroom Performance Assessments and Scoring Rubrics. Practical Assessment, Resea4ch \& Evaluation, 8(14). Retrieved May 14, 2008 from http://PAREonline.net/getvn.asp?v=8\&n=14 .

10. Paranto, S. and Neumann, H. (2006). Management Information Systems: Assessing Student Placement \& Performance. Issues in Information Systems, VII(1), 2006. Published by the International Association for Computer Information Systems. ISSN: 1529-7314.

11. Paranto, S. and Neumann, H. (2006). Evaluating the Tools utilized in Assessing Student Information Systems Competencies in a RapidlyChanging Global Economy. Winter Conference of the International Academy of Business and
Public Administration Disciplines Conference Proceedings, 3(1), p. 421-429, January 2006. ISSN: 1545-4836.

12. Schuh, Alexander V. (2004). Equity and Technology Literacy in the Mid-Atlantic Region, p. 1. [online] Available: www.temple.edu/ marttec/assistance/pd/schuh_paper_web.pdf

13. Skills Assessment Manager (SAM). Site accessed February 2008. [online] Available: samcentral.course.com/computer_concepts.cfm

14. Sonntag, G. and Meulemans, Y. (2003). Planning Assessment. In E. Fuseler Avery (Ed.), Assessing Student Learning Outcomes for Information Literacy Instruction in Academic Institutions (pp. 6-21). Association of College and Research Libraries, a Division of the American Library Association, Chicago.

15. Valenti, S., Cuchiarelli, A., and Panti, M. (2002). Computer Based Assessment Systems Evaluation via the ISO9126 Quality Model. Journal of Information Technology Education, Vol. 1(3), 2002. Published by the Informing Science Institute, Santa Rosa, California USA.

\section{APPENDIX A PRE-/POST-TEST TASKS/QUESTIONS}

\section{Spreadsheet Tasks}

1. Use an Advanced Filter to display only the records that meet the following criteria: winter AND more than 5 days. Enter the criteria in row 3 of the Criteria range (enter the criteria for winter first, then for more than 5 days). Filter the list in place; use A5:H45 as the list range and A2:H3 as the criteria range.

2. Use the PMT function to calculate a monthly payment in cell F15 based on the loan amount in cell C15. The loan term is 10 years; the annual interest rate is $6 \%$. Refer to the cells on the worksheet in the formula and do not include values for FV or Type. The payment value will display as a negative number.

3. In cell F19, use the COUNTIF function to determine how many programs had more than 25 attendees.

4. Make changes to the template in the following order: change the text font in cell A1 to Times New Roman, change the widths of columns A through D to AutoFit using the AutoFit Selection command, change the fill color of cells A3:D3 to green (row 2, column 4), and change the font color in cells A3:D3 to white (row 5, column 8).

5. Tile the two workbooks so both appear on screen. Save the arrangement as a workspace named "Data+Charts" to the default folder. 
6. Use the Data Consolidate command to sum the data from the Jan and Feb workbooks in the Consolidate workbook. Use the labels in the left column. Set up a link to the source workbooks.

7. For cells B6:B8, name each cell according to the label in the column to the left. Cell B6 will be named Contributions, cell B7 will be named Grants, and cell B8 will be named Total Revenue. (Do not close the Define Name dialog box until all three ranges have been named.)

8. Place a formula that uses absolute references in cell D4 that will return the ranking $\mathrm{A}, \mathrm{B}$, or $\mathrm{C}$ based on the date in Column C. The ranking information is in the lookup table in F4:G6. (The lookup table is sorted in the correct order.) Copy the formula to the range D5:D18.

9. Create a one-input data table in the range A10:D24, using the value in cell D2 as the column input.

\section{Presentation Software Tasks}

10. Change the chart on Slide 4 into a column chart. Have the columns be 2-D and side by side.

11. On Slide 4, add an organization chart. In the top box, type "Tour Choices" and in three subordinate boxes, type "Moivaro Crater","Mt. Village", and "Safari Spa".

12. Drag to select all ungrouped objects in the film cassette clip art on Slide 6 and then regroup the objects.

13. Change the color scheme for all the slides from gray to dark blue (row 1, column 2).

14. Apply the Appear animation scheme (under the "Subtle" heading) to slides 2 and 3.

15. Apply the Comb Horizontal slide transition to slides 2 and 3 at the same time.

16. Change the titles to the font named Verdana on both the Slide Master and the Title Master. Close the Master View by using the Close Master View button when finished.

\section{Word Processing Tasks}

17. Apply the "Heading 1" style to the words "Good Sports" in first line of the document.

18. Change the text from three-column to twocolumn format.

19. Format the drawing canvas to change the horizontal alignment to right. (Do not right-click the canvas.)

20. Use WordArt to add "Good Sports" to the top of the page. Use the orange upward-slanting style (row 5, col 4), and then change the shape to Arch Up (Pour).

21. Create a MS Word chart using the data in the table. Use the default style of chart.
22. Change the part of the newsletter text starting from "MidTex Soccer" to a section with twocolumn format. Keep "Good Sports Member News" and the blue border in a single column. Apply a continuous section break before applying the formatting.

23. Using the paragraph that begins with "Get with media," create a style for the bulleted list items. The style should incorporate the bullet style, the line spacing, and the indentation settings. Name the style "To do".

24. Merge the current document with the data in 'mergelist.doc" in the My Data source folder. Insert fields for "Inside address" and "Salutation" where indicated. Print all the letters.

25. Use Mail Merge Wizard to create mailing labels using mergelist.doc as the data source. Use Avery 5160 address labels. Do not insert the postal bar code. Print labels for all the records in the data source.

\section{Database Tasks}

26. Create a new table in Design View. Setup two fields, a date field labeled "Date" and a Text field labeled "Special Activity". Close and save the table. Name this table "Activity". Do not set a primary key.

27. Create a Tabular Autoform based on the Circulation Table.

28. Add a combo box to the Books form that selects values from a list for the Type field. The possible values are 1,2 , and 3 . Place the combo box in the Detail section at 1 on the horizontal ruler and 1 on the vertical ruler. Assign the name, Type, as the label for the combo box.

29. Create a query in Design View to list, left to right, the Title, Author, and Price of all books priced under 20. All the data can be found in the "Books" table.

30. The Title field in this report can contain data that is longer than the width of the field. Use the property sheet to modify this field so that data can be spread over multiple lines.

31. Add a combo box to this form which will display both Type and Description. Use the Type table as the lookup values source. Sort the list alphabetically by Type. Store the data in the Type field and accept the default combo box name given by the wizard.

32. Modify the report design to group the report by Borrower\#. Include a Borrower\# group header and group footer. Sort the report by Borrower\# (ascending) and then by Date Borrowed (descending). Close the Sorting and Grouping window. 


\section{Internet / Website Development Questions}

33. HTML uses a set of special instructions called to define the characteristics of items such as formatted text, images, hyperlinks, and forms.
A. tags
B. texts
C. notes
D. lists

34. Each Web page on a Web site has a unique address called a URL, which stands for
A. Unique Relational Location
B. Utility Resource List
C. Uniform Resource Locator
D. Utility RAM Location

35. Extra rows can be added to the bottom of a table on a Web page by positioning the insertion point in the last column of the last row and then pressing

A. the CTRL key

B. the TAB key

C. the ALT key

D. SHIFT $+\mathrm{S}$

36. Which of the following is the default alignment for newly inserted items in a table cell?
A. left-aligned
B. right-aligned
C. centered
D. top-aligned

37. A horizontal rule refers to which of the following?

A. the requirement of all table headings to display horizontally in rows

B. a small, thin line that spans the entire Web page

C. both a and b

D. none of the above

38. Which of the following is the first step in creating an image map?
A. defining a hotspot on an image
B. selecting an image to use
C. assigning URLs to all hotspots
D. drawing secondary hotspots

39. When you highlight hotspots on an image, a hotspot that is selected displays
A. as solid black
B. with a black outline
C. as dimmed
D. as transparent

40. Which of the following is a reason for encountering broken hyperlinks?
A. the Web server on which the file resides could be out of service
B. the file that is the target of the hyperlink could have been deleted or renamed
C. the Web server on which the file resides could have had its Internet address changed
D. all of the above 